\title{
Curative and Palliative Surgery in Advanced Carcinoma of the Large Bowel*
}

\author{
HAROLD ELLIS
}

British Medical fournal, 1971, 3, 291-293

Carcinoma of the large bowel is the second commonest killing cancer in the United Kingdom and accounts for some 14,000 deaths annually; probably, therefore, most clinicians will see many examples of patients at an advanced and often apparently hopeless stage of this disease. Many such cases are unfortunately, indeed beyond any help, and others may obtain some relief from cytotoxic therapy or radiotherapy; but there is a third category where worth-while palliative surgery can be carried out or even "curative" resection performed. This third category is considered here.

The patients fall into three groups: those with extensive local disease; those with distant metastases, particularly in the liver; and those who have developed apparent recurrence of the disease after previous successful resection.

\section{Advanced Local Disease}

An important question that faces a surgeon dealing with cancer at laparotomy is What constitutes inoperability? Frequently invasion of adjacent structures vitiates curative surgery, but this general rule meets its most frequent exceptions in tumours of the large bowel, where resection of the growth itself together

*From a lecture given at the B.M.A. Annual Clinical Meeting, Aberystwyth, on 3 April 1971.

Westminster Hospital, London S.W.1

HAROLD ELLIS, M.CH., F.R.C.s., Professor of Surgery with involved abdominal wall, bladder, small intestine, stomach, or female genitalia may give long-term survival. El-Domeiri and Whiteley, ${ }^{1}$ for example, quoted the cases of 10 patients undergoing right hemicolectomy for carcinoma of the caecum in which adjacent infiltrated anterior abdominal wall required resection; at the time of their report seven patients were still alive, five of them having survived five years. Van Prohaska and his colleagues ${ }^{2}$ reviewed 225 patients undergoing resection of the large bowel; 21 (9\%) of these required resection of one or more adjacent structures. In these 21 patients there was only one operative death. Fourteen survived for between 2 and 13 years, of whom nine survived for more than five years.

We have now operated on five patients with carcinoma of the right colon invading the duodenum; in two a coloduodenal fistula was present, in one patient the right kidney was also involved and required nephrectomy, and in another the anterior abdominal wall and a loop of small intestine were also invaded and were resected. All underwent successful resection and at the time of writing four were still alive, one having survived four years without sign of recurrence.

Cooke $^{3}$ pointed out that fixation and apparent inoperability of a large-bowel tumour may be due entirely to inflammatory adhesions to adjacent viscera, which may settle down after a preliminary colostomy, allowing a subsequent curative resection. It is interesting that Jensen and his colleagues, ${ }^{4}$ in a study of 60 patients requiring removal of adjacent structures in the course of resection of colonic neoplasms, found that 23 had only inflammatory adhesions, and 13 of these patients were alive five years later; the remaining 37 patients were confirmed to have malignant invasion of the adjacent tissues, and only five of these survived for five years.

Obviously, therefore, the surgeon must not abandon too readily the possibility of resection of large-bowel tumours even if at first the prospects seem daunting. Nor should he be too depressed by the age and general condition of the patient, since we have performed several successful resections of painful or obstructing colonic and rectal neoplasms in octogenarians and in one indomitable woman aged 90. 


\section{Presence of Liver Metastases}

What should the surgeon do when he detects secondary deposits in the liver at exploration on a patient who has a resectable tumour in the large bowel? Many surgeons decide against any further procedure or recommend only some sort of short circuit or colostomy, their attitude being that the patient is doomed and should not be submitted to major surgery. In contrast there are others who advocate radical surgery wherever possible, including resection of the liver metastases, if these are confined to one or other lobe, or the use of cytotoxic drugs, given either systemically or by liver perfusion. Until recently it has been difficult to decide what attitude to adopt because of the surprising lack of information about the natural history of the untreated patient against which to assess the effects of therapy. Fortunately facts concerning survival times in both treated and untreated cases are now being reported. Flanagan and Foster ${ }^{5}$ reported that the mean survival of 26 patients with carcinoma of the colon having liver metastases and not undergoing treatment was six months. Jaffe and his colleagues 6 noted an average survival of only five weeks in 14 such cases. In our own series ${ }^{7}$ all six patients submitted only to laparotomy were dead within five months. Similar figures were quoted by Bacon and Martin8 and by Bengmark and Hafstrom.9

Has resection of the primary lesion any effect on these depressing figures? Modlin and Walker ${ }^{10}$ compared 35 patients undergoing palliative resection of large-bowel tumours with 41 untreated cases. They found no significant increase in survival time. Nevertheless, they included patients with hopeless local, lymphatic, and peritoneal spread in their resection group as well as 22 patients with only liver deposits. They did note, however, that palliative resection gave worthwhile relief of symptoms. McSherry and his colleagues ${ }^{11}$ noted a mean survival time of 1.7 months in patients undergoing only laparotomy for carcinoma of the colon and rectum, compared with 8.9 months in those subjected to palliative colostomy or bypass and 12.4 months in those undergoing palliative resection. In the Westminster Hospital series 716 out of 38 patients who underwent excision of the rectum in the face of liver metastases survived for more than 12 months, the longest being 66 months. Of 48 patients undergoing resection of colonic neoplasms 16 survived for more than 12 months, the longest being 53 months; thus 32 out of a total of 86 patients undergoing palliative resection lived for over one year. Recently Cady and his colleagues ${ }^{12}$ reported very similar figures, with $33 \%$ of their patients achieving a one-year survival and $14 \%$ living for two years or more after palliative resection in the presence of liver deposits.

It is true that figures such as the ones I have quoted are not strictly comparable, because the surgeon faced with very extensive liver metastases is less likely to submit his patient to surgery than in a case where only one or two deposits are present and where the prognosis appears to be more hopeful. Thus we still need more accurate information about the natural history of patients with liver deposits graded according to the extent of hepatic involvement. Perhaps just as important as actual survival time, however, is that excision of the primary lesion, wherever this is technically feasible, will remove or prevent unpleasant local symptoms of obstruction, fistula formation, invasion of adjacent viscera, etc., and so improve the quality of the patient's life in his remaining months.

Now and then the surgeon will see a patient at laparotomy with an apparently solitary deposit in one or other lobe of the liver whose primary tumour of the large bowel is itself resectable. He should not hesitate under such circumstances to resect part of the liver, and he should be strengthened in his endeavour by reports of very long-term survivals after this procedure. ${ }^{13} 1415$ Foster16 recently reviewed the published results of liver resection for cancer. This survey included 123 patients with resections for metastatic cancer of whom 83 had primary tumours of the colon or rectum; $47 \%$ were alive at two years and $21 \%$ survived for five years. These cases included three reports of liver resection in continuity with an adjacent invading colonic carcinoma. One patient died of cancer in less than two years, but the other two were alive at 13 months and 9 years postoperatively.

\section{Apparent Recurrence after Resection}

There can be few more depressing experiences to the medical practitioner than to see a patient who has undergone an apparently successful resection of a neoplasm return with all the familiar pointers which are suggestive of recurrence of the disease. Loss of weight, abdominal pain, the development of an abdominal mass or of abdominal distension, or the presence of jaundice are all sinister features which fill the surgeon, the patient's own doctor, the relatives, and the patient himself with gloom. While it is true that most of these patients will indeed have developed hopeless recurrent disease, it is important to remember that a minority may not be in this unfortunate category. Under these circumstances one should go through the following catechism: (1) Could these features be due to some completely benign condition?; (2) Could the patient have developed a second operable primary tumour?; (3) Could the recurrence still be resectable?; (4) Even if the recurrence is irremovable can the surgeon offer relief from symptoms-for example, by a short circult or colostomy?

Simply because a patient has had a resection of cancer in the past does not necessarily mean that every symptom he subsequently develops must indicate recurrent disease. We have encountered abdominal masses due to deeply placed sterile abscesses months or even years after resection of colonic neoplasm. ${ }^{17}$ Obstructive symptoms may be due to an anastomotic stricture or due to adhesions-indeed Ketcham and his colleagues $^{18}$ found that $18 \%$ of 117 patients with intestinal obstruction after treatment for cancer had some benign obstructive condition at laparotomy. Even jaundice, on rare occasions, may be due to some entirely benign condition; in particular, stones in the common bile duct.

Carcinoma of the large bowel has a sinister reputation for the development of either a synchronous or metachronous second primary tumour. Hughes, ${ }^{19}$ for example, in a series of 1,015 cases of carcinoma of the large bowel, reported that 25 had a second tumour present in the bowel at the time of the initial operation and that nine further patients subsequently developed a second carcinoma in the colon or rectum in a time interval of 2 to 20 years after their first resection.

Recurrence of the original tumour at the anastomotic line is well recognized after excision of large-bowel tumours and is especially likely to occur in restorative resection of the rectum due to implantation of tumour cells at the suture line; despite all precautions this still occurs in about $2 \%$ of cases. ${ }^{20} 21$ The development of a metachronous second tumour in the bowel or of an anastomotic recurrence by no means precludes a successful second resection, and indeed many such cases have been reported. Similarly an implantation deposit in the abdominal scar after colonic resection or in the perineal wound after an abdominoperineal excision of the rectum may be perfectly amenable to potentially curative surgical excision.

Finally, patients with all the misery of intestinal obstruction resulting from inoperable tumour recurrence should be considered for palliative short circuit or colostomy. Study of the plain films of the abdomen may help the surgeon to decide whether or not some useful palliative procedure might be worthwhile.

\section{REVIEW OF PERSONAL SERIES}

Over the past eight years we have re-explored 27 cases of patients who had undergone previous "curative" resections for large-bowel carcinoma because of the clinical diagnosis of re- 
currence of malignant disease. Our result gives some idea of the encouragements and disappointments that one might expect from a policy when further laparotomy is offered to all but those with obvious hopeless disseminated disease.

Three patients were found to have non-malignant conditions with no evidence of recurrence of the original disease; there was one example of obstruction due to adhesions, one a granulomatous stricture at the anastomosis, and one a twisted ovarian cyst. The first two patients remained alive and well but the third died three years later of congestive cardiac failure. Two patients had developed entirely new tumours presenting as abdominal masses. One of these had a carcinoma of the body of the uterus who a year after hysterectomy developed recurrences in the vault of the vagina and died; the other had a renal carcinoma and died a few months after nephrectomy from widespread metastases.

Four patients developed metachronous tumours in another part of the large bowel which were suitable for resection. One died of recurrences 18 months later. The other three were alive and well four years, three years, and two months after resection. Eight patients developed a recurrence at or near the anastomosis which was resected. Three of these died within the year and a fourth at 15 months. One patient was lost sight of and at the time of writing one was still immediately postoperative. Two were living at 18 months and four years after resection, free from apparent recurrence.

Two patients with recurrences at the anastomosis with intestinal obstruction could only be short-circuited and both died within three months of operation. Five patients had excisions of recurrences in the abdominal scar, the perineum, ovary, or pelvis. Four died at 3,10,13, and 15 months of metastatic disease, but the patient with a perineal metastatis after abdominoperineal excision of the rectum was free of disease over two years later.

Three patients were found to have disseminated deposits at second laparotomy, and these were treated with either radiotherany or cytotoxic therapy or a combination of the two. One was alive and well eight months later, one died at three months, and one died at one year.

To sum up this small series of 27 patients submitted to re-exploration, nine achieved long-term good results and two remained wcll within a year of their second operation.

\section{Conclusion}

We feel that there is much to gain and little to lose in offering laparotomy to patients with apparent recurrence of large-bowel cancer. The occasional case with benign disease alone is worth all the endeavour, and certainly the occasional long-term survival of patients with resection of recurrence at the anastomosis or a second tumour elsewhere in the bowel is encouraging. Even in those cases where long-term survival has not been achieved it has often been possible to remove or short-circuit painful obstructive lesions. Even if at exploration a surgically hopeless situation is found, laparotomy delimits the extent of the problem, allows consideration of further treatment in the way of radiotherapy or cytotoxic therapy, gives some idea of prognosis, and, at the very least, gives the patient and his family the knowledge that no effort has been spared before giving the final, hopeless prognosis.

\section{References}

1 El-Domeiri, A., and Whiteley, H. W., Cancer, 1970, 26, 552.

Van Prohaska, J., Govostis, M. C., and Wasick, M., Surgery, Gynecology and Obstetrics, 1953, 97, 177.

${ }^{3}$ Cooke, R. V., Annals of the Royal College of Surgeons of England, 1956 18,46

${ }^{4}$ Jensen, H. E., Balslev, I., and Nielsen, J., Acta Chirurgica Scandinavica, $1970,136,431$.

${ }^{5}$ Flanagan, L., and Foster, J. H., American fournal of Surgery, 1967, 113,

B Jaffe, B. M., Donegan, W. L., Watson, F., and Spratt, J. S., Surgery, Gynecology and Obstetrics, $1968,127,1$.

7 Oxley, E. M., and Ellis, H., British Fournal of Surgery, 1969, 56, 149.

8 Bacon, H. E., and Martin, P. V., Diseases of the Colon and Rectum, 1964, 7, 211 .

o Bengmark, S., and Haftstrom, L., Cancer, 1969, 23, 198.

10 Modlin, J., and Walker, H. S. J., Cancer, 1949, 2, 767.

11 McSherry, C. K., Cornell, G. N., and Glenn, F., Annals of Surgery, 1969, 169,502 .

12 Cady, B., Monson, D. O., and Swinton, N. W., Surgery, Gynecology and Obstetrics, 1970, $131,697$.

13 Peden, J. C., and Blalock, W. N., Cancer, 1963, 16, 1133.

14 Woodington, G. F., and Waugh, J. M., American fournal of Surgery, 1963, $105,24$.

15 Friesen, S. R., Hardin, C. A., and Kittle, C. F., Surgery, 1967, 61, 203.

${ }^{16}$ Foster, J. H., Cancer, 1970, 26, 493.

17 Cronin, K, and Ellis, H., British Medical fournal, 1958, 2, 1319.

18 Ketcham, A. S., Hoye, R. C., Pilch, Y. H., and Morton, D. L., Cancer, $1970,25,406$.

19 Hughes, E. S. R., British Medical Fournal, 1963, 2, 9.

${ }_{20}$ Kughes, E. S. R., British Medical Fournal, 1963, 2,

${ }_{21}^{20}$ Hale, J. E., Proceedings of the Royal Society of Medicine, 1969, 62, 713.

\title{
Anaesthetic Staffing and Training Requirements in Scotland
}

\author{
GEOFFREY D. PARBROOK
}

\section{British Medical fournal, 1971, 3, 293-296}

\section{Summary}

In Scotland there is an average of 12 consultant vacancies and 14 Fellows qualifying per year, but these are insufficient to meet all the vacancies as several emigrate

\footnotetext{
University Department of Anaesthetics, Royal Infirmary, Glasgow, C.4

GEOFFREY D. PARBROOK, M.B., F.F.A. R.C.s. Senior Lecturer
}

or return abroad. The existing registrar and senior registrar establishments are inadequate to meet the numbers of consultants required if full allowance is made for special factors, such as the high proportion of women graduates and the rising proportion of overseas trainees.

A backlog of understafing in Scotland relative to England and Wales is shown by comparison of the ratio of anaesthetists to surgeons. The existing rate of expansion of $6 \%$ per year must continue for many years or be increased if stafing levels are to come into line with those elsewhere in Britain. 